\title{
How Practice Facilitation Strategies Differ by Practice Context
}

\author{
Ann M. Nguyen, $P h D M P H^{7}$ (D) , Allison Cuthel, $\mathrm{MPH}^{2}$, Deborah K. Padgett, PhD MPH MA ${ }^{3}$, \\ Paulomi Niles, CNM LM MPH'4, Erin Rogers, DrPH' , Hang Pham-Singer, PharmD5, \\ Diane Ferran, MD MPH', Sue A. Kaplan, JD', Carolyn Berry, PhD' , and Donna Shelley, \\ $M D M P H^{7}$
}

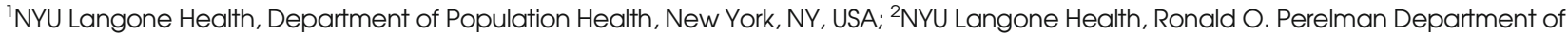
Emergency Medicine, New York, NY, USA; ${ }^{3}$ Silver School of Social Work, New York University, New York, NY, USA; ${ }^{4}$ Rory Myers College of Nursing, New York University, New York, NY, USA; ${ }^{5}$ New York City Department of Health and Mental Hygiene, New York, NY, USA; ${ }^{6}$ Community Health Care Association of New York State, New York, NY, USA.
\end{abstract}

\begin{abstract}
BACKGROUND: Practice facilitation is an implementation strategy used to build practice capacity and support practice changes to improve health care outcomes. Yet, few studies have investigated how practice facilitation strategies are tailored to different primary care contexts.

OBJECTIVE: To identify contextual factors that drive facilitators' strategies to meet practice improvement goals, and how these strategies are tailored to practice context.

DESIGN: Semi-structured, qualitative interviews analyzed using inductive (open coding) and deductive (thematic) approaches. This study was conducted as part of a larger study, HealthyHearts New York City, which evaluated the impact of practice facilitation on adoption of cardiovascular disease prevention and treatment guidelines.
\end{abstract}

PARTICIPANTS: 15 facilitators working in two practice contexts: small independent practices (SIPs) and Federally Qualified Health Centers (FQHCs).

MAIN MEASURES: Strategies facilitators use to support and promote practice changes and contextual factors that impact this approach.

KEY RESULTS: Contextual factors were described similarly across settings and included the policy environment, patient needs, site characteristics, leadership engagement, and competing priorities. We identified four facilitation strategies used to tailor to contextual factors and support practice change: (a) remain flexible to align with practice and organizational priorities; (b) build relationships; (c) provide value through information technology expertise; and (d) build capacity and create efficiencies. Facilitators in SIPs and FQHCs described using the same strategies, often in combination, but tailored to their specific contexts.

Prior Presentation: This work was presented at the 2018 AcademyHealth Conference on the Science of Dissemination and Implementation in Health as a poster and the 2018 International Conference on Practice Facilitation as an oral presentation.

Electronic supplementary material The online version of this article (https://doi.org/10.1007/s11606-019-05350-7) contains supplementary material, which is available to authorized users.

Received April 16, 2019

Accepted September 10, 2019

Published online October 21, 2019
CONCLUSIONS: Despite significant infrastructure and resource differences between SIPs and FQHCs, the contextual factors that influenced the facilitator's change process and the strategies used to address those factors were remarkably similar. The findings emphasize that facilitators require multidisciplinary skills to support sustainable practice improvement in the context of varying complex health care delivery settings.

KEY WORDS: practice facilitation; qualitative; implementation.

J Gen Intern Med 35(3):824-31

DOI: $10.1007 /$ s11606-019-05350-7

(C) Society of General Internal Medicine 2019

\section{INTRODUCTION}

Primary care practices are under tremendous pressure to change the way their services are organized and delivered in an effort to increase adoption of evidence-based guidelines and improve care quality. ${ }^{1,2}$ Practice facilitation is an emergent implementation strategy for supporting primary care practices' efforts to meet quality improvement (QI) goals. ${ }^{3-}$ ${ }^{10}$ Implementation strategies are methods or techniques used to enhance the adoption, implementation, and sustainability of a clinical program or practice. ${ }^{11}$ The Expert Recommendations for Implementing Change (ERIC) study identified practice facilitation as a core implementation strategy; however, the study also noted that a lack of clarity in defining implementation strategies like facilitation limits our ability to replicate findings in real-world settings. ${ }^{12,13}$

Facilitation is the "deliberate and valued process of interactive problem-solving and support."14 More recently, Berta et al. provided a theoretically-grounded definition of facilitation that places context at the center ${ }^{15}$ : "Facilitation is a goaloriented, context-dependent social process for implementing new knowledge into practice or organizational routines." Multi-level contextual factors are known to influence the facilitation process. ${ }^{16-23}$ Yet, only a few studies have described the strategies used by facilitators to tailor the facilitation process to practice context in real-world settings. ${ }^{7,24,25}$ The present study 
is the first to examine facilitation strategies in small independent practices and to further contrast facilitation in small versus larger practices.

HealthyHearts New York City (HHNYC), funded through the Agency for Healthcare Research and Quality's EvidenceNOW initiative, was a mixed-methods study of the effectiveness of practice facilitation to increase capacity among two types of primary care practices - small independent practices (SIPs) and Federally Qualified Health Centers (FQHCs) - to implement evidence-based guidelines for preventing and managing cardiovascular disease (CVD). ${ }^{5}$ HHNYC is a partnership among the NYU School of Medicine; the Primary Care Information Project (PCIP), a bureau of the New York City Department of Health and Mental Hygiene ${ }^{26}$; and the Community Health Care Association of New York State (CHCANYS) ${ }^{27}$ PCIP enrolled 257 SIPs, and CHCANYS enrolled 19 sites from nine FQHCs. SIPs and FQHCs differ in significant ways, most notably in that SIPs have far fewer resources to dedicate towards QI efforts.

The HHNYC intervention was informed by the Chronic Care $\mathrm{Model}^{28}$ and patient-centered medical home and included 13 on-site visits over 12 months, in which practice facilitation was used as the implementation strategy. Each facilitator supported their assigned practices to: 1) optimize use of electronic health records (EHRs) and data system platforms to monitor and drive change, 2) provide guideline updates and patient materials related to CVD risk factors, and 3) redesign workflows to facilitate integration of evidence-based guidelines into routine care. All facilitators were encouraged to tailor their strategies to local context (herein referred to as "facilitation strategies") and achieved high rates of fidelity to the site visit schedule. ${ }^{29}$

This paper uses qualitative methods to identify contextual factors that drive facilitators' strategies, and how these strategies are tailored to practice context. Tailoring, defined as "very minor changes to an intervention that leave all major intervention principles or components intact" ${ }^{30}$ in the context of guideline implementation studies is common, but understudied and underreported. The inclusion of SIPs and FQHCs in our study provides a unique opportunity to compare how strategies are driven by different practice contexts.

\section{METHODS}

\section{Study Design and Setting}

NYU researchers conducted semi-structured interviews with all 15 facilitators who implemented the intervention: 13 from PCIP working solely with SIPs and 2 from CHCANYS working solely with FQHCs. NYU researchers presented the purpose of the interviews to all facilitators during a team meeting with organizational leadership approval. Facilitators received individual e-mail invitations and were offered a \$25 honorarium; participation was not mandatory and not part of their usual job. The NYU School of Medicine Institutional Review Board approved the study.

\section{Study Sample}

Facilitator characteristics are shown in Table 1. Most had prior experience working as facilitators and had completed a practice facilitation certificate program. ${ }^{31}$ Ten facilitators had 2 or fewer years of experience as facilitators; however, all were overseen by experienced managers and received a 2 week training at the start and on-going training throughout. Table 2 summarizes the characteristics of the settings. SIPs differed mostly by number of staff, ownership, and infrastructure. Sixty-six percent of SIPs were solo clinician practices and had an average of 4 support staff. In contrast, most FQHC sites $(72.2 \%)$ had five or more clinicians and an average of 24 support staff. FQHC sites are part of a larger umbrella FQHC organization that provides support for practice transformation and QI-related activities. For this project, each FQHC site assembled a site-level QI team led by a chief medical officer (CMO) to work the facilitator. SIPs did not have designated QI teams.

\section{Data Collection}

The interviews were conducted as part of a larger assessment of the facilitation process. The interview guide was informed by the Consolidated Framework for Implementation Research (CFIR) ${ }^{16}$ an implementation science framework organized

Table 1 Practice facilitator characteristics

\begin{tabular}{ll}
\hline \hline & $\mathrm{N}(\%)$ \\
Age $(n=15)$ & $1(7.1)$ \\
$18-24$ & $9(64.3)$ \\
$25-34$ & $3(21.4)$ \\
$35-44$ & $2(14.3)$ \\
$45-54$ & $4(26.7)$ \\
Sex $(\mathrm{n}=15)$ & $11(73.3)$ \\
Male & \\
Female & $1(6.7)$ \\
Highest level of education $(\mathrm{n}=15)$ & $9(60.0)$ \\
High school diploma & $5(33.3)$ \\
Bachelor's degree & \\
Master's/Graduate degree & \\
Completion of University of Buffalo Practice & $11(78.6)$ \\
Facilitation Training $(n=14)$ & $3(21.4)$ \\
Yes & \\
No & $5(33.3)$ \\
Previous years of experience as a facilitator $(\mathrm{n}=15)$ & $5(33.3)$ \\
< 1 year & $4(26.7)$ \\
1-2 years & $1(6.7)$ \\
3-5 years & \\
6+ years & $2(40.0)$ \\
Additional language spoken $(n=5)$ & $1(20.0)$ \\
Spanish & $1(20.0)$ \\
Mandarin & $1(20.0)$ \\
Cantonese & \\
Other & $3(23.1)$ \\
Ethnicity (n=14) & $11(84.6)$ \\
Hispanic/Latino & \\
Non-Hispanic/Latino & $3(21.4)$ \\
Race $(\mathrm{n}=14)$ & $6(42.9)$ \\
White & $4(28.6)$ \\
Black & $1(7.1)$ \\
Asian & \\
Other & \\
\hline
\end{tabular}


Table 2 Practice characteristics

\begin{tabular}{lll}
\hline \hline & Small Independent Practices & Federally Qualified Health Center Sites \\
\hline & $N=257$ & $N=19$ \\
$\mathrm{n}(\%)$ & $\mathrm{n}(\%)$ \\
Number of clinicians & $149(65.9)$ & $0(0.0)$ \\
Solo & $66(29.2)$ & $5(27.8)$ \\
$2-5$ & $11(4.9)$ & $13(72.2)$ \\
$5+$ & $228(92.7)$ & $0(0.0)$ \\
Practice ownership & $0(0.0)$ & $18(94.7)$ \\
Independent & $18(7.3)$ & $1(5.3)$ \\
Health maintenance organization & $6.0(12.4)$ & $24.1(25.6)$ \\
Other, e.g., hospital/health system & $97(37.7)$ & $5(26.3)$ \\
Full-time equivalent of support staff, Mean (SD) & $121(47.3)$ & $14(73.7)$ \\
Part of accountable care organization & $135(52.7)$ & $5(26.3)$ \\
Medically underserved area designation & $118(46.1)$ & $16(88.9)$ \\
Yes & $138(53.9)$ & $2(11.1)$ \\
No & $17.0(26.1)$ & $18.2(27.6)$ \\
Patient-centered medical home recognition & $47.5(26.9)$ & $55.7(22.0)$ \\
Yes & No &
\end{tabular}

Note: Data for patient-centered medical home recognition was obtained directly from the Primary Care Innovation Project for the Small Independent Practices and from the study's Practice Survey for the Federally Qualified Health Center sites. Where values do not add up to "N," there is missing data

into domains likely to influence intervention implementation. We formulated questions to address the domains (see the Appendix for an interview guide). Two trained research staff (AC \& PN) conducted the interviews during the intervention period. Interviews were $1-\mathrm{h}$, audio recorded with permission, and transcribed verbatim. Recordings and transcripts were stored on a secure server accessible only to the research team, and interview results were de-identified. No member of the team had pre-existing relationships with the facilitators.

\section{Analytic Approach}

The data analysis started with all team members reading transcripts independently to use an inductive approach (open coding; i.e., agnostic of CFIR) ${ }^{32}$ to create a codebook focused on the research objective (i.e., identify facilitation strategies). To minimize investigator bias, we created a multi-disciplinary team with varied backgrounds (medicine, public health, law, and social work) and checked for consistency in data interpretation across team members. Next, two members (AC \& DS) used the resulting codebook to code the transcripts. Questions were resolved through discussion with a third team member (ER). The team met to review memos and codes using an inductive approach (thematic content analysis) to identify key themes of contextual factors that drove the facilitation strategies and strategies used by facilitators to tailor the intervention to context. The inductive approach is considered appropriate for identifying repeated patterns of meaning across data. ${ }^{33}$ Analyses were conducted using ATLAS.ti qualitative software. ${ }^{34}$ Throughout the analysis, emerging themes were shared with PCIP during weekly meetings and with CHCANYS via email to enhance external validity; both confirmed the themes and that selected quotes were representative of their internal experiences. Our reporting adheres to the Consolidated Criteria for Reporting Qualitative Research standards. ${ }^{35}$

\section{RESULTS}

While SIPs and FQHCs are vastly different primary care settings, facilitators in both described the same set of contextual factors affecting their approach: the policy environment, patient needs, site characteristics, leadership engagement, and competing priorities. Table 3 includes representative quotes in the two settings that describe how contextual factors impacted the facilitation process for improving adoption of multiple guidelines for CVD prevention and treatment.

Facilitators from both settings also described applying similar overarching facilitation strategies to tailor the intervention and change process to practice context: (a) remain flexible to align with practice and organizational priorities; (b) build relationships; (c) provide value through information technology (IT) expertise; and (d) build capacity and create efficiencies. There was variation, however, in how facilitators applied these strategies in the two different practice settings. Moreover, facilitators often used these strategies in combination. Below, we describe the strategies and note when contextual factors were reported as specifically influential (bolded).

\section{Facilitation Strategy 1: Remain Flexible to Align with Practice and Organizational Priorities}

Practices agreed to enroll in the study largely because the intervention and aims were aligned with practice goals. However, facilitators found that working with sites to implement the intervention required that they remain flexible to align 
Table 3 Summary of the two practice settings using representative quotes from facilitators

\begin{tabular}{|c|c|c|}
\hline Contextual Factors & Quote from Small Independent Practice (SIP) & $\begin{array}{l}\text { Quote from Federally Qualified Health Center } \\
\text { (FQHC) Site }\end{array}$ \\
\hline $\begin{array}{l}\text { licy Environment: State and local } \\
\text { centive programs }\end{array}$ & $\begin{array}{l}\text { "We always have questions about when is } \\
\text { Meaningful Use gonna start? What is this } \\
\text { MIPS-MACRA* incentive payment? We always get } \\
\text { bombarded with those questions." (SIP08) }\end{array}$ & $\begin{array}{l}\text { "With this new administration and the environment } \\
\text { being very unclear as to where we are going to go } \\
\text { and if our health centers are safe as far as how much } \\
\text { funding they'll get to keep their doors open, that's a } \\
\text { real concern." (FQHC18) }\end{array}$ \\
\hline $\begin{array}{l}\text { Patient Needs: Low income, minority, } \\
\text { and immigrant patient populations } \\
\text { with diverse needs }\end{array}$ & $\begin{array}{l}\text { "I do not really work with many English-speaking } \\
\text { practices. Some of the materials aren't available in } \\
\text { those languages, which can be challenging." (SIP01) }\end{array}$ & $\begin{array}{l}\text { "How do you have conversations with patients on } \\
\text { adhering to medication when their needs are, 'I do } \\
\text { not have a place to call home right now?"” } \\
\text { (FQHC18) }\end{array}$ \\
\hline $\begin{array}{l}\text { Site Characteristics: Limited } \\
\text { resources, including protected time } \\
\text { and organizational structure }\end{array}$ & $\begin{array}{l}\text { "A lot of these small practices are just the doctor and } \\
\text { his wife or just one person and an office manager." } \\
\text { (SIP08) }\end{array}$ & $\begin{array}{l}\text { "We have deliverables after every quality } \\
\text { improvement team meeting. Trying to get them to } \\
\text { practice some things in between the times that we } \\
\text { meet and identifying or getting dedicated time for that } \\
\text { has been challenging." (FQHC18) }\end{array}$ \\
\hline $\begin{array}{l}\text { Leadership Engagement: Inconsistent } \\
\text { engagement }\end{array}$ & $\begin{array}{l}\text { "Having to get a buy-in from a member who's really } \\
\text { critical, like the administrator or the doctor them- } \\
\text { selves is challenging." (SIP03) }\end{array}$ & $\begin{array}{l}\text { "You try to find your allies. Maybe it's not the } \\
\text { medical director. Maybe it's the data lead who's just } \\
\text { passionate about data and is able to galvanize the } \\
\text { team. Maybe it's the nurse manager." (FQHC19) }\end{array}$ \\
\hline $\begin{array}{l}\text { Competing Priorities: Day-to-day } \\
\text { tasks and other quality improvement } \\
\text { projects }\end{array}$ & $\begin{array}{l}\text { "[The intervention component] has not been } \\
\text { implemented "cause the front desk or the office } \\
\text { manager has a million other things on their plate." } \\
\text { (SIP11) }\end{array}$ & $\begin{array}{l}\text { "Our sites are strapped for time. They're super busy. } \\
\text { They're always reacting to something that's } \\
\text { happening on-site." (FQHC18) }\end{array}$ \\
\hline
\end{tabular}

* MIPS-MACRA = Merit-based Incentive Payment System - Medicare Access and CHIP Reauthorization Act

HHNYC with a range of competing priorities that practices were juggling. This strategy also demonstrates the added value of engaging in the facilitation process, but it manifested differently in the two settings as a result of differences in infrastructure (site characteristics).

For example, in contrast to the $\mathrm{FQHC}$ facilitators, based on PCIP's knowledge of their practices, SIP facilitators were specifically trained to meet a broader range of practice needs created by gaps in staffing and QI expertise. A facilitator noted, "The practice staff doesn't usually have a dedicated QI person." (SIP02) SIPs often asked facilitators to help with a range of IT and administrative issues that were not related to HHNYC. As one facilitator described: "You have to remain flexible and just adapt to different situations. If it's something I can help them with, I will start with that... so they trust me, so they see that I'm a resource." (SIP01) Another facilitator described spending time on a problem unrelated to HHNYC: "We actually called up eCW [EHR vendor] during the [HHNYC] visit. It's important to help them solve these problems." (SIP14) In the SIP setting, in which there are few staff, facilitators were asked to function not only as "teachers, resource providers, and coaches" but also as "staff extenders." (SIP02).

In contrast, when flexibility was mentioned by $\mathrm{FQHC}$ facilitators, it was regarding having to change expectations about what practices were able to accomplish between meetings (competing priorities) - "Flexibility [is needed] because... you can have a plan for the week, but things just don't go the way you think they're going to go." (FQHC18) - as well as during meetings: "The agenda changes when you work with sites that only have an hour to spare." (FQHC19). In addition, FQHC facilitators worked with a local QI team dedicated to this project, and they were not expected to provide assistance outside of the scope of the project. (FQHC19) Rather, the facilitator role was "to introduce them [QI team] to the ABCS measures, to talk about the survey component... We are a form of external support. The work is really on them." (FQHC19).

\section{Facilitation Strategy 2: Build Relationships}

Building relationships with the practice staff and engaging leadership was core to the practice facilitation process. This strategy again manifested differently in the two settings, driven by infrastructure (site characteristics) and practice needs.

For SIP facilitators in particular, the process of building relationships overlapped with the need to remain flexible, as a way to build trust, strengthen relationships, and increase engagement and retention. For example, when practices identified language barriers as a patient need, facilitators searched for supplemental CVD materials in "many different languages." (SIP06) Trust and perceived value of facilitation led to more receptive visits: "Showing them [doctors] little tips and tricks that can help them with their electronic health record or any other quality improvement measures... helps me get in the door... Once I gain their trust, it's like, 'Hey, when you gonna come back?'” (SIP08).

For the FQHC facilitators, the multilevel organizational structure created challenges in terms of building relationships and engaging local leadership. Typically, FQHC QI projects are focused at the organizational level, not the site level. For this study, however, facilitators worked with individual FQHC sites to build local capacity to make practice changes. FQHC facilitators described relationship building as critical to understanding the local QI team's capacity: "Practice facilitation is a lot about understanding people and how to work well with 
people and elicit action from them. So much of our role is relationship building and management." (FQHC19) However, in working at the site level, facilitators learned that the CMO for each local QI team did not always have decision-making power: "[The CMO was] not as empowered as I thought... I'm finding this to be common. The team didn't necessarily feel like they could make the changes." (FQHC18) The facilitator elaborated, "There's a lot of resistance in the C-suite... I thought just having a CMO in the team would be the answer to getting this to the top of the leadership team, but that didn't work." The facilitators described having to also develop working relationships with the FQHC umbrella organization's QI team to "advocate with leadership [at the organizational level] to get protected time so that providers [at the site level] can do quality improvement work." (FQHC18).

\section{Facilitation Strategy 3: Provide Value through IT Expertise}

Facilitators from both settings described providing value through health IT expertise. This helped practices improve documentation and data validity, and created more efficient workflows that were aligned with concurrent QI projects (competing priorities) and external regulatory requirements (policy environment).

Due to the small staff and lack of on-site IT expertise (site characteristics) in SIPs, providing this type of support was central to the SIP facilitation process. Facilitators needed to offer "a lot of tech support [to] help the practices understand how to use their clinical information. There are a lot of changes within the practice in terms of workflows based on the whole technology component." (SIP10) SIP facilitators reinforced how important having expertise in this area was in the context of supporting small practices: "In order to teach them, you have be familiar with the quality measures they are working on and have a vast knowledge of the EHR and its features - what the EHR can and can't do." (SIP07) Again, because of the small staff and gaps in expertise, SIP facilitators faced the on-going challenge of balancing capacity building with simply making changes themselves: "I remember in one of my... practices, going in and teaching staff how to run reports. A provider was asking me if I can do it. I told her that that wasn't the role that I was there for, but I did tell her that I would do it for the visit just to get the staff used to it, and then hand it off." (SIP12).

In contrast to SIPs, however, FQHC facilitators were often engaged at the macro-level, in offering health IT support. FQHCs were all linked to a data warehouse with tools that supported QI processes (e.g., quality measures dashboards). Facilitators worked with both the umbrella FQHC and FQHC sites (site characteristics) make sure they knew how to access and use EHR tools through the warehouse. A facilitator summarized: "The biggest part of our curriculum is to get them to utilize our data warehouse... develop their comfort level [with] running reports and measuring progress." (FQHC18).

\section{Facilitation Strategy 4: Build Capacity and Create Efficiencies}

Building capacity and creating efficiencies - both core functions of practice facilitation ${ }^{36}$ - was an overarching strategy, which created a foundation for the other strategies. Many SIPs and FQHC sites did not "have the time" (FQHC19) (site characteristics) to fully engage with facilitators on this project. By focusing on capacity building and creating efficiencies through workflow redesign, facilitators were able to help "take some of the load off of" staff members, which led to staff "feeling more important and connected to their work." (SIP13).

In SIPs, facilitators actively tailored the intervention to align with competing priorities by creating efficiencies through workflow redesign. For example, facilitators bundled HHNYC measures with Meaningful Use, a concurrent QI project (policy environment): "Just having them understand these are also the tasks that overlap with Meaningful Useclinical summaries, transition to care, looking at referrals... It's actually overlapping, and it's helping [the practice] in other areas for quality improvement... and impacting reimbursement." (SIP10).

Despite the FQHCs' infrastructure and a designated QI team, providers and staff did not have protected time (site characteristics) to work on QI initiatives: "Even if they tell you, 'We have weekly meetings or monthly meetings,' they don't have a chance to really discuss [the changes]... That was very eye-opening for me that they don't really talk." (FQHC19) However, FQHC facilitators were able to apply strategies that were similar to the SIP facilitators to help sites make changes to improve efficiency. A FQHC facilitator described that mapping workflows with the QI project teams helped build capacity by giving the teams more "ownership of... responsibilities. Knowing who does what helped streamline the process." (FQHC18).

\section{DISCUSSION}

The facilitator role is complex and requires a wide range of skills and knowledge to support primary care transformation while tailoring their process to practice context. Our findings add to the current literature by further outlining strategies facilitators apply in supporting practices as tailored to two very different practice settings. Several researchers, as well as the Agency for Health Care Research and Quality, have outlined practice facilitation activities and core competencies, but few have obtained data from the facilitator's perspective on how these activities are implemented in the context of complex health care delivery environments. ${ }^{19,36}$

One of the more interesting findings was that, despite significant differences between FQHCs and SIPs, the contextual factors that influenced the facilitator strategies used to address those factors were remarkably similar. However, within these different practice contexts, the way facilitators applied these strategies differed. SIPs had fewer resources and staff 
which challenged facilitators to balance teaching and capacity building with making the changes needed to the EHR, for example, and doing other tasks for the practice. ${ }^{30} \mathrm{FQHCs}$ have a QI infrastructure that allowed facilitators to focus on capacity building. Yet, for both settings, competing priorities resulted in little time to focus on QI and required facilitators to develop context-specific strategies. Addressing this on-going issue is important to advancing practice transformation goals. Practice facilitation may be one part of a solution to support practices that are overwhelmed by external and internal demands.

Prior research has described building relationships and building capacity as core facilitator activities (i.e., a part of their training). ${ }^{37}$ However, the degree of flexibility required in working with SIPs in particular is under-recognized in the literature. Moreover, the nature of SIPs, with a very small number of staff and skill gaps, required engaging in practice support activities outside the scope of the project. Facilitators working with both types of sites described the importance of remaining flexible to align with organizational infrastructure and priorities as critical to the facilitation process. Such a strategy was core to building the relationships necessary for demonstrating the value proposition of taking time away from a practice's other priorities to engage in facilitation.

The emergence of health IT support as a theme is new to the literature on facilitation, which suggests that practice facilitation training and processes should explicitly incorporate this skillset. It also highlights the ongoing need for capacity in the use of health IT to improve quality of care, which is core to practice transformation efforts. What was notable was that even in FQHC sites, there was a need for support in terms of teaching the local sites how to use data to drive change. Despite a strong QI infrastructure at the $\mathrm{FQHC}$ organizational level, this expertise was not necessarily disseminated to local site staff. Given the opportunity to participate in facilitation, FQHCs recognized the value of and need to build local capacity to drive innovation and QI.

To the best of our knowledge, only a few studies have reported on practice facilitation strategies. Liddy et al. (2014) similarly examined facilitators' perspectives on the implementation of CVD guidelines in primary care practices. ${ }^{25}$ The authors identified "barriers" faced during the facilitation process: practice accessibility, organizational behavior, practice engagement, resistance to change, and competing priorities. Practice accessibility was not a concern in HHNYC which is likely due to the existing relationships that PCIP and CHCANYS have with practices. The other barriers were consistent with our findings. However, our study revealed that facilitators do not use the term "barriers" when describing their experiences; rather, they spoke about tailoring to the real-world context of primary care practices (Table 3 ). This perspective, and reframing of barriers as contextual factors, seems important in terms of acknowledging that tailoring is necessary to ensure "fit" between intervention and local context. $^{38}$

In another study on facilitator strategies, ${ }^{6}$ the authors distinguished the facilitation strategies used for health IT versus practice transformation interventions. In contrast, we found that facilitators can bring more value to the practice by leveraging their IT skills, rather than considering IT and practice transformation as separate. Since that study was completed, EHRs have become ubiquitous. Even if facilitators do not have this specific skill, a practice facilitation program needs to have access to health IT expertise.

Our findings are consistent with interviews with SIP providers enrolled in HHNYC. ${ }^{39}$ Overall, providers perceived the assistance they received to optimize their EHR for QI and financial goals and connecting them to the external health care environment as two of the main benefits of facilitation services.

This study demonstrates that the facilitation process is one of on-going tailoring and adaptation that is often not acknowledged or captured. Future research should incorporate recently published taxonomies for defining adaptations and the core components of implementation strategies like practice facilitation to systematically capture adaptation for different populations/contexts. ${ }^{38}$ This would facilitate analysis of the impact of practice facilitation on practice improvement outcomes. Further, this work suggests there is a potential to define practice context typologies that can guide specific facilitation strategies across similar health care settings. Research is needed to expand on our findings on how contexts drives the facilitation process to further advance the value of practice facilitation as an implementation strategy.

\section{Limitations}

There were several limitations. Due to the setting of New York City and relatively small sample size (15 facilitators), findings may not be generalizable to all primary care practices. However, we believe that the scope and diversity of the practices render our findings more generalizable and transferable to future interventions. The study sample is small, but given the large number of sites that facilitators worked with, we believe the findings have relevance to primary care practices more generally. As with any qualitative study, interviews and data interpretation may have been influenced by investigator bias. Described in the methods section, we took steps to minimize bias by utilizing a multidisciplinary team and checking interpretation across team members and external partners.

\section{CONCLUSION}

Different types of practices are struggling with similar contextual factors related to meeting QI improvement and transformation goals, but these issues were amendable to similar practice facilitation strategies tailored to those contexts. The findings of our study emphasize that facilitators require multidisciplinary skills to support sustainable practice improvement within varying complex health care delivery settings. 
Contributor: We thank Clare Liddy for providing feedback on a manuscript draft.

Corresponding Author: Ann M. Nguyen, PhD MPH; NYU Langone Health, Department of Population Health, New York, NY, USA (e-mail: Ann.Nguyen@nyulangone.org).

Funder This project was supported by grant number 1R18HSO23922 from the Agency for Healthcare Research and Quality (AHRQ). The content is solely the responsibility of the authors and does not necessarily represent the official views of the AHRQ.

\section{Compliance with Ethical Standards:}

Conflict of Interest: $D F$ discloses a patent for The Companion Guide for Quality Improvement Leaders (Copyright TX 8-648-833 issued to Community Health Care Association of New York State).

\section{REFERENCES}

1. Bodenheimer T, Pham HH. Primary Care: Current Problems and Proposed Solutions. Health Aff. 2010;29(5):799-805. https://doi.org/ $10.1377 /$ hlthaff.2010.0026

2. Lau R, Stevenson F, Ong BN, et al. Achieving change in primary care-causes of the evidence to practice gap: systematic reviews of reviews. Implement Sci. 2016;11(40). https://doi.org/10.1186/s13012016-0396-4

3. Baskerville NB, Liddy C, Hogg W. Systematic Review and Meta-Analysis of Practice Facilitation Within Primary Care Settings. Ann Fam Med. 2012;10(1):63-74. https://doi.org/10.1370/afm. 1312

4. Liddy C, Hogg W, Singh J, et al. A real-world stepped wedge cluster randomized trial of practice facilitation to improve cardiovascular care. Implement Sci. 2015;10(1):150. https://doi.org/10.1186/s13012-0150341-y

5. Shelley DR, Ogedegbe G, Anane S, et al. Testing the use of practice facilitation in a cluster randomized stepped-wedge design trial to improve adherence to cardiovascular disease prevention guidelines: HealthyHearts NYC. Implement Sci. 2015;11(1):88. https://doi.org/10. 1186/s13012-016-0450-2

6. Chase SM, Nutting PA, Crabtree BF. How to Solve Problems in Your Practice with a New Meeting Approach. Fam Pract Manag. 2010;17(2):31-34.

7. Hemler JR, Hall JD, Cholan RA, et al. Practice Facilitator Strategies for Addressing Electronic Health Record Data Challenges for Quality Improvement: EvidenceNOW. J Am Board Fam Med. 2018;31(3):398409. https://doi.org/10.3122/JABFM.2018.03.170274

8. Laferriere $\mathbf{D}$, Liddy $\mathbf{C}$, Nash $\mathbf{K}$, Hogg $\mathbf{W}$. Navigating change: how outreach facilitators can help clinicians improve patient outcomes. J Am Board Fam Med. 2012;25(2):232-237. https://doi.org/10.3122/ jabfm.2012.02.110192

9. Harvey G, Lynch E. Enabling Continuous Quality Improvement in Practice: The Role and Contribution of Facilitation. Front Public Heal. 2017;5:27. https://doi.org/10.3389/fpubh.2017.00027

10. Wang A, Pollack T, Kadziel LA, et al. Impact of Practice Facilitation in Primary Care on Chronic Disease Care Processes and Outcomes: a Systematic Review. J Gen Intern Med. 2018;33(11):1968-1977. https:// doi.org/10.1007/s11606-018-4581-9

11. Curran GM, Bauer M, Mittman B, Pyne JM, Stetler C. Effectivenessimplementation Hybrid Designs: Combining Elements of Clinical Effectiveness and Implementation Research to Enhance Public Health Impact. Med Care. 2012;50(3):217-226. https://doi.org/10.1097/MLR. Ob013e3182408812

12. Powell BJ, Waltz TJ, Chinman MJ, et al. A refined compilation of implementation strategies: results from the Expert Recommendations for Implementing Change (ERIC) project. Implement Sci. 2015;10(1):21. https://doi.org/10.1186/s13012-015-0209-1

13. Proctor EK, Powell BJ, McMillen JC. Implementation strategies: recommendations for specifying and reporting. Implement Sci. 2013;8(1):139. https://doi.org/10.1186/1748-5908-8-139

14. Stetler CB, Legro MW, Rycroft-Malone J, et al. Role of "external facilitation" in implementation of research findings: a qualitative evaluation of facilitation experiences in the Veterans Health Administration. Implement Sci. 2006; 1(23). https://doi.org/10.1186/1748-5908-1-23

15. Berta W, Cranley L, Dearing JW, Dogherty EJ, Squires JE, Estabrooks CA. Why (we think) facilitation works: insights from organizational learning theory. 2015. https://doi.org/10.1186/ s13012-015-0323-0

16. Damschroder LJ, Aron DC, Keith RE, Kirsh SR, Alexander JA, Lowery JC. Fostering implementation of health services research findings into practice: a consolidated framework for advancing implementation science. Implement Sci. 2009;4(1):50. https://doi.org/10.1186/1748-5908-4-50

17. Kitson AL, Rycroft-Malone J, Harvey G, McCormack B, Seers K, Titchen A. Evaluating the successful implementation of evidence into practice using the PARiHS framework: theoretical and practical challenges. Implement Sci. 2008;3(1):1. https://doi.org/10.1186/17485908-3-1

18. Liddy C, Rowan M, Valiquette-Tessier S-C, Drosinis P, Crowe L, Hogg W. Improved Delivery of Cardiovascular Care (IDOCC): Findings from Narrative Reports by Practice Facilitators. Prev Med Reports. 2017;5:214219. https://doi.org/10.1016/J.PMEDR.2016.12.018

19. Dogherty EJ, Harrison MB, Graham ID. Facilitation as a Role and Process in Achieving Evidence-Based Practice in Nursing: A Focused Review of Concept and Meaning. Worldviews Evidence-Based Nurs. 2010;7(2):76-89.

20. Rycroft-Malone $\mathbf{J}$, Seers $\mathbf{K}$, Chandler $\mathbf{J}$, et al. The role of evidence, context, and facilitation in an implementation trial: implications for the development of the PARIHS framework. Implement Sci. 2013;8(1):28. https://doi.org/10.1186/1748-5908-8-28

21. Jacobs SR, Weiner BJ, Bunger AC. Context matters: measuring implementation climate among individuals and groups. Implement Sci. 2014;9(1):46. https://doi.org/10.1186/1748-5908-9-46

22. Dickinson LM, Dickinson WP, Nutting PA, et al. Practice Context Affects Efforts to Improve Diabetes Care for Primary Care Patients: A Pragmatic Cluster Randomized Trial. J Gen Intern Med. 2015;30(4):476482. https://doi.org/10.1007/s11606-014-3131-3

23. Tomoaia-Cotisel A, Scammon DL, Waitzman NJ, et al. Context matters: the experience of 14 research teams in systematically reporting contextual factors important for practice change. Ann Fam Med. 2013;11(Suppl 1):S115-23. https://doi.org/10.1370/afm.1549

24. Chase SM, Crabtree BF, Stewart EE, et al. Coaching strategies for enhancing practice transformation. Fam Pract. 2015;32(1):75-81. https://doi.org/10.1093/fampra/cmu062

25. Liddy CE, Blazhko V, Dingwall M, Singh J, Hogg wE. Primary care quality improvement from a practice facilitator's perspective. BMC Fam Pract. 2014;15(1):23. https://doi.org/10.1186/1471-2296-15-23

26. NYC Health. Primary Care Information Project. https://wwwl.nyc.gov/ site/doh/providers/resources/primary-care-information-project.page. Accessed December 29, 2018.

27. Community Health Care Association of New York State. http://www. chcanys.org/. Accessed December 29, 2018.

28. Wagner EH, Austin BT, Davis C, Hindmarsh M, Schaefer J, Bonomi A. Improving Chronic Illness Care: Translating Evidence into Action. Health Aff. 2001;20(6):64-78. https://doi.org/10.1377/HLTHAFF.20.6.64

29. Shelley D, Cuthel A, Corwin M, Siman N, Cleland C, Berry C. Measuring fidelity in HealthyHearts NYC: A complex intervention using practice facilitation in primary care. In: 11th Annual Conference on the Science of Dissemination and Implementation in Health. Arlington; 2018. https://academyhealth.confex.com/academyhealth/2018di/ meetingapp.cgi/Paper/29041. Accessed 3-5 December 2018.

30. Baumann AA, Cabassa LJ, Stirman SW. Adaptation in Dissemination and Implementation Science. In: Brownson RC, Colditz GA, Proctor EK, eds. Dissemination and Implementation Research in Health: Translating Science to Practice. Vol 1. Oxford: Oxford University Press; 2017. https:// doi.org/10.1093/oso/9780190683214.001.0001

31. Petersen D, Babalola L, Crosson J, Taylor E, Peikes D. Training Program Summary: Millard Fillmore College Practice Facilitator Certificate Program. Case Studies of Exemplary Primary Care Practice Facilitation Training Programs. https://www.ahrq.gov/professionals/ prevention-chronic-care/improve/system/pfcasestudies/fillmore.html. Published 2014. Accessed December 28, 2018.

32. Creswell JW, Clark VLP. Designing and Conducting Mixed Methods Research. 4th Ed. Thousand Oaks: SAGE Publications, Inc; 2017. 1483344371

33. Boyatzis R. Transforming Qualitative Information: Thematic Analysis and Code Development. Thousand Oaks: Sage; 1998.

34. ATLAS.ti Scientific Software Development GmbH. ATLAS.ti. 2017. https://atlasti.com/. 
35. Tong A, Sainsbury $\mathbf{P}$, Craig J. Consolidated criteria for reporting qualitative research (COREQ): a 32-item checklist for interviews and focus groups. Int J Qual Heal Care. 2007;19(6):349-357. https://doi. org/10.1093/intqhe/mzm042

36. Knox L, Brach C. The Practice Facilitation Handbook: Training Modules for New Facilitators and Their Trainers. Rockville; 2013. https://www.ahrq.gov/ sites/default/files/publications/files/practicefacilitationhandbook.pdf. Accessed November 15, 2018.

37. Ritchie MJ, Dollar KM, Miller CJ, et al. Using Implementation Facilitation to Improve Care in the Veterans Health Administration (Version 2). 2017. https://www.queri.research.va.gov/tools/implementa-
tion/Facilitation-Manual.pdf. Accessed June 11, 2019.

38. Chambers DA, Norton WE. The Adaptome: Advancing the Science of Intervention Adaptation. Am J Prev Med. 2016;51(4):S124-S131. https://doi.org/10.1016/J.AMEPRE.2016.05.011

39. Rogers ES, Cuthel AM, Berry CA, Kaplan SA, Shelley DR. Clinician perspectives on the benefits of practice facilitation for small primary care practices. Ann Fam Med. 2019; 17(Suppl 1):S17-23.

Publisher's Note Springer Nature remains neutral with regard to jurisdictional claims in published maps and institutional affiliations. 